\title{
The peopling of the last Green Sahara revealed by high-coverage resequencing of trans-Saharan patrilineages
}

Eugenia D’Atanasio ${ }^{1,2+}$, Beniamino Trombetta ${ }^{1 \dagger}$, Maria Bonito $^{1}$, Andrea Finocchio $^{3}$, Genny Di Vito ${ }^{1}$, Mara Seghizzi ${ }^{1}$, Rita Romano ${ }^{4}$, Gianluca Russo ${ }^{4}$, Giacomo Maria Paganotti ${ }^{5,6}$, Elizabeth Watson ${ }^{7}$, Alfredo Coppa ${ }^{8}$, Paolo Anagnostou ${ }^{8,9}$, Jean-Michel Dugoujon ${ }^{10}$, Pedro Moral ${ }^{11}$, Daniele Sellitto ${ }^{12}$, Andrea Novelletto ${ }^{3}$ and Fulvio Cruciani ${ }^{1,12^{*}}$ (D)

\begin{abstract}
Background: Little is known about the peopling of the Sahara during the Holocene climatic optimum, when the desert was replaced by a fertile environment.

Results: In order to investigate the role of the last Green Sahara in the peopling of Africa, we deep-sequence the whole non-repetitive portion of the $Y$ chromosome in 104 males selected as representative of haplogroups which are currently found to the north and to the south of the Sahara. We identify 5,966 mutations, from which we extract 142 informative markers then genotyped in about 8,000 subjects from 145 African, Eurasian and African American populations. We find that the coalescence age of the trans-Saharan haplogroups dates back to the last Green Sahara, while most northern African or sub-Saharan clades expanded locally in the subsequent arid phase.

Conclusions: Our findings suggest that the Green Sahara promoted human movements and demographic expansions, possibly linked to the adoption of pastoralism. Comparing our results with previously reported genome-wide data, we also find evidence for a sex-biased sub-Saharan contribution to northern Africans, suggesting that historical events such as the trans-Saharan slave trade mainly contributed to the mtDNA and autosomal gene pool, whereas the northern African paternal gene pool was mainly shaped by more ancient events.
\end{abstract}

Keywords: MSY, Target next generation sequencing, Green Sahara, Trans-Saharan haplogroups

\section{Background}

The Sahara desert is the widest hot desert on Earth and covers about one-third of the African continent, from the Atlantic coast to the Red Sea. Over the past millennia, the Sahara underwent strong climatic fluctuations, alternating arid and humid phases. During the humid periods, referred to as "Green Sahara" or "African humid periods", the landscape was characterised by the presence of savannah, forests and an extensive system of rivers and lakes [1-3]. A large amount of paleoecological and paleoanthropological evidence indicates that the

\footnotetext{
* Correspondence: fulvio.cruciani@uniroma1.it

${ }^{\dagger}$ Equal contributors

'Dipartimento di Biologia e Biotecnologie "C. Darwin", Sapienza Università di Roma, Rome, Italy

${ }^{12}$ Istituto di Biologia e Patologia Molecolari, CNR, Rome, Italy

Full list of author information is available at the end of the article
}

fertile environment probably enabled the occupation of the Saharan area by fauna and hominins since the Miocene [3-5].

The most recent Green Sahara period occurred in the Holocene, in a time frame from about 12 thousand of years ago (kya) to about 5 kya. This phase has been denominated the "Holocene climatic optimum" and is the most well-documented past climatic change [2, 6]. Human settlement across the Sahara in this period is testified by archaeological evidence, such as rock engravings, lithic and bone tools and pottery [7].

After the African humid period, the climatic conditions became rapidly hyper-arid and the Green Sahara was replaced by the desert, which acted as a strong geographic barrier against human movements between northern and sub-Saharan Africa. 
A consequence of this is that there is a strong differentiation in the $\mathrm{Y}$ chromosome haplogroup composition between the northern and sub-Saharan regions of the African continent. In the northern area, the predominant Y lineages are J-M267 and E-M81, with the former being linked to the Neolithic expansion in the Near East and the latter reaching frequencies as high as $80 \%$ in some north-western populations as a consequence of a very recent local demographic expansion [8-10]. On the contrary, sub-Saharan Africa is characterised by a completely different genetic landscape, with lineages within E-M2 and haplogroup B comprising most of the Y chromosomes. In most regions of sub-Saharan Africa, the observed haplogroup distribution has been linked to the recent ( 3 kya) demic diffusion of Bantu agriculturalists, which brought E-M2 sub-clades from central Africa to the East and to the South [11-17]. On the contrary, the sub-Saharan distribution of B-M150 seems to have more ancient origins, since its internal lineages are present in both Bantu farmers and non-Bantu hunter-gatherers and coalesce long before the Bantu expansion [18-20].

In spite of their genetic differentiation, however, northern and sub-Saharan Africa share at least four patrilineages at different frequencies, namely A3-M13, E-M2, E-M78 and R-V88.

A3-M13 is typical of eastern Africa, where it is found with a frequency as high as $40 \%$ and is prevalent in the Nilo-Saharan populations, in particular among Nilotic pastoralists [14, 18, 21]. A3-M13 chromosomes have also been observed in central and northern Africa, at frequencies ranging from 1 to $7 \%$ [12, 18, 22, 23]. Outside Africa, this haplogroup has been found at very low frequency in both the Middle East and Sardinia [23-30].

As described above, E-M2 is a sub-Saharan clade which has been often associated with the Bantu expansion. However, E-M2 chromosomes have also been found at low frequencies (2-10\%) in northern Africa [8, 9, 22, 23, 31, 32].

E-M78 is a widespread lineage, with significant frequencies in Africa, Europe and the Middle East [33, 34]. Within the African continent, three E-M78 sub-clades (E-V22, E-V12 and E-V264) show different frequencies in different regions. E-V22 is mainly an eastern African sub-haplogroup, with frequencies of more than $80 \%$ in the Saho population from Eritrea, but it has also been reported in Egypt and Morocco [34-36]. E-V12 is relatively frequent in northern and eastern Africa, but it has also been reported outside Africa at lower frequencies [33-35]. The vast majority of the eastern African E-V12 chromosomes belong to the internal clade E-V32, which has also been observed in northern and central Africa at very low frequencies [12, 33-35]. E-V264 is subdivided into two sub-clades: E-V65, common in northern Africa; and E-V259, which includes few central African chromosomes [33-35].
R-V88 has been observed at high frequencies in the central Sahel (northern Cameroon, northern Nigeria, Chad and Niger) and it has also been reported at low frequencies in northwestern Africa [37]. Outside the African continent, two rare R-V88 sub-lineages (R-M18 and R-V35) have been observed in Near East and southern Europe (particularly in Sardinia) [30, 37-39]. Because of its ethno-geographic distribution in the central Sahel, R-V88 has been linked to the spread of the Chadic branch of the Afroasiatic linguistic family [37, 40].

From a genetic point of view, the use of variability in the present-day male-specific portion of the human $\mathrm{Y}$ chromosome (MSY) to infer past population dynamics across the Sahara is complicated by two major factors: 1 ) the onset of the hyper-arid conditions caused the depopulation of the Sahara; 2) the regions immediately northward and southward of the Sahara have experienced extensive demographic expansions after the African humid period, which have led to the increase in frequency of different $\mathrm{Y}$ haplogroups, partially concealing the pre-existing genetic composition [32, 41].

In this context, rare $\mathrm{Y}$ lineages with a relic geographic distribution can be highly informative regarding human migrations across the Sahara. Thus, considering their frequency distribution, the four trans-Saharan lineages A3-M13, E-M2, E-M78 and R-V88 could represent the remains of the Saharan MSY genetic landscape before the desertification, contrary to the usual interpretation involving recent gene flow events such as the transSaharan Arab slave trade [42-44].

In order to investigate the role of the last Green Sahara in the peopling of Africa, we performed targeted next generation sequencing (NGS) of $\sim 3.3 \mathrm{Mb}$ of $104 \mathrm{Y}$ chromosomes mostly belonging to these four lineages. We also analysed the geographic distribution of 142 informative single nucleotide polymorphisms (SNPs) by genotyping about 8000 male subjects from 145 worldwide populations (including 17 populations from literature), with a particular focus on the African ethnic groups. Our findings were consistent with the hypothesis that the Green Sahara allowed extensive human movements, excluding recent historical events, such as the Arab slave trade, as a major determinant of the male gene pool of present-day northern African populations.

\section{Results}

\section{Phylogenetic tree and the four trans-Saharan clades}

For the phylogenetic tree reconstruction and time estimates, we used $150 \mathrm{Y}$ chromosomes. The samples were analysed for $\sim 3.3 \mathrm{Mb}$ of the X-degenerated portion of the MSY (Fig. 1) and belonged to different datasets: 104 Y chromosomes from our lab collection (77 of them belonging to the four trans-Saharan haplogroups) and 46 publicly available high-coverage sequences, including 


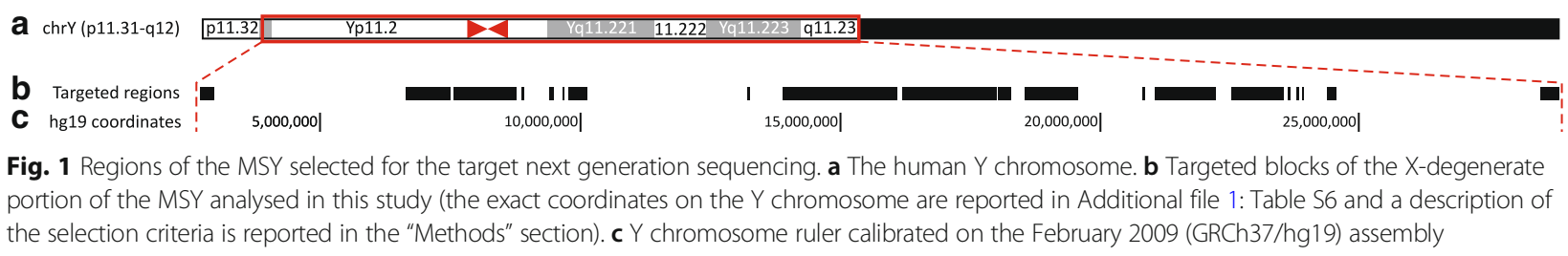

four precisely radiocarbon-dated ancient specimens as calibration points [45-49] (Additional file 1: Table S1).

In the set of 104 samples from our lab collection, we identified 5966 SNPs. Interestingly, 3044 variants (51 \%) out of the 5966 were not reported in previous studies $[30,48,50,51]$ and this figure is significantly greater than that reported by Hallast et al. [50] (51 vs $36.6 \%$, Chi-squared test: $\left.p<2.2 \times 10^{-16}\right)$, despite the fact the experimental approaches were similar (target sequencing) and the number of sequenced samples by Hallast and collegues [50] was about four times higher (Additional file 2: Figure S1). After the inclusion of the 46 samples from the literature [45-49], the total number of variants increased to 7544 (Additional file 1: Table S2). We used all 7544 SNPs in the whole set of 150 subjects to reconstruct a maximum parsimony tree (Fig. 2a), which was found to be coherent with the recently published world-wide Y phylogenies [48, 51].

By calibration with the four archeologically dated specimens, we obtained a mutation rate of $0.735 \times 10^{-9} /$ site/ year, which is consistent with previously published estimates $[47,51,52]$ and which was used to obtain an accurate estimate of the coalescence age of the tree nodes, with a particular focus on the four trans-Saharan clades. We obtained the time estimates using two different approaches: Rho statistics (Table 1) and the BEAST method. We performed two different BEAST runs, under a strict or a relaxed clock, respectively (Additional file 1: Table S3). The obtained point values were found to be highly concordant (Pearson test, $\mathrm{R}^{2}>0.99 ; p<2.2 \times 10^{-16}$ ), as previously observed [19] (Additional file 2: Figure S2). For this reason, hereafter we only report and discuss the time estimates based on the Rho statistics (Fig. 2b).

A3-M13 phylogeny is characterised by a first bifurcation separating branches 19 and 37 about 10.75 kya. Interestingly, branch 19 has a widespread distribution, harbouring lineages from within and outside the African continent, and is dated to 10.24 kya, suggesting a role of the humid period in the diffusion of this clade. On the contrary, branch 37 only includes samples from the Horn of Africa (Ethiopia, Eritrea, Djibouti and Somalia) and is dated to $8.43 \mathrm{kya}$.

The topology of E-M2 is characterised by a main multifurcation (downstream to branch 71), dating back to the beginning of the last Green Sahara (10.53 kya) and including all the deep-sequenced samples except one (branch 70), consistent with the tree reported in phase 3 of the 1000 Genomes Project [51]. However, we found 11 subclades (branches 72, 73, 74, 75, 76, 79, 81, 82, 95, 98 and 99) which share no markers with the 262 E-M2 chromosomes analysed by Poznik and collegues [51]. It is worth noting that branches 72 and 81 are two deep sister lineages within the E-M2 main multifurcation (Fig. 2) and both of them include chromosomes from northern Africa. Similarly, the other terminal lineages absent in the 1000 Genomes Project's tree are mainly represented by samples from northern Africa or, to a lesser extent, from the northernmost regions of sub-Saharan Africa (i.e. the central Sahel) (Fig. 2b).

The phylogenetic structure of E-M78 has been resolved in a recent study [35]; however, we obtained further information about the relationships within the EV12 sub-clade. The former E-V12* chromosomes form a monophyletic cluster (branch 125), dated to 8.98 kya and sister to E-V32 (branch 131), which in turn is further subdivided into three sister clades (branches 132, 138 and 143). While branches 132 and 138 have been found in eastern Africa, where E-V32 is more frequent, branch 143 only includes samples from central Sahel (Fig. 2b).

Finally, the R-V88 lineages date back to $7.85 \mathrm{kya}$ and its main internal branch (branch 233) forms a "star-like" topology ("Star-like" index $=0.55$ ), suggestive of a demographic expansion. More specifically, 18 out of the 21 sequenced chromosomes belong to branch 233, which includes eight sister clades, five of which are represented by a single subject. The coalescence age of this subbranch dates back to 5.73 kya, during the last Green Sahara period. Interestingly, the subjects included in the "star-like" structure come from northern Africa or central Sahel, tracing a trans-Saharan axis. It is worth noting that even the three lineages outside the main multifurcation (branches 230, 231 and 232) are sister lineages without any nested sub-structure. The peculiar topology of the R-V88 sequenced samples suggests that the diffusion of this haplogroup was quite rapid and possibly triggered by the Saharan favourable climate (Fig. 2b).

In general, our NGS results and time estimates show that the large majority of the lineages shared by northern Africans and sub-Saharan Africans coalesced during the last Green Sahara period. Conversely, after 5 kya, we mainly found lineages restricted to either northern or sub-Saharan regions, with few exceptions (Fig. 2b). 
a

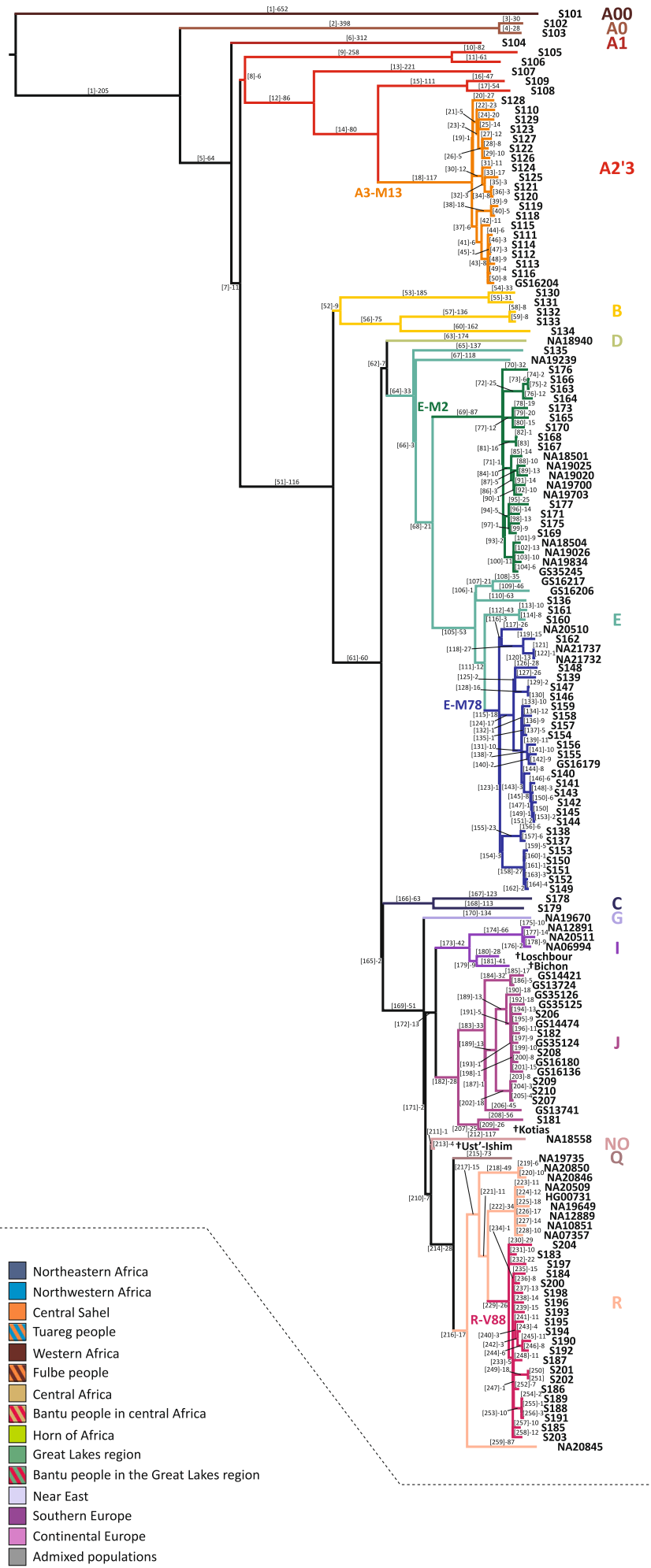

b
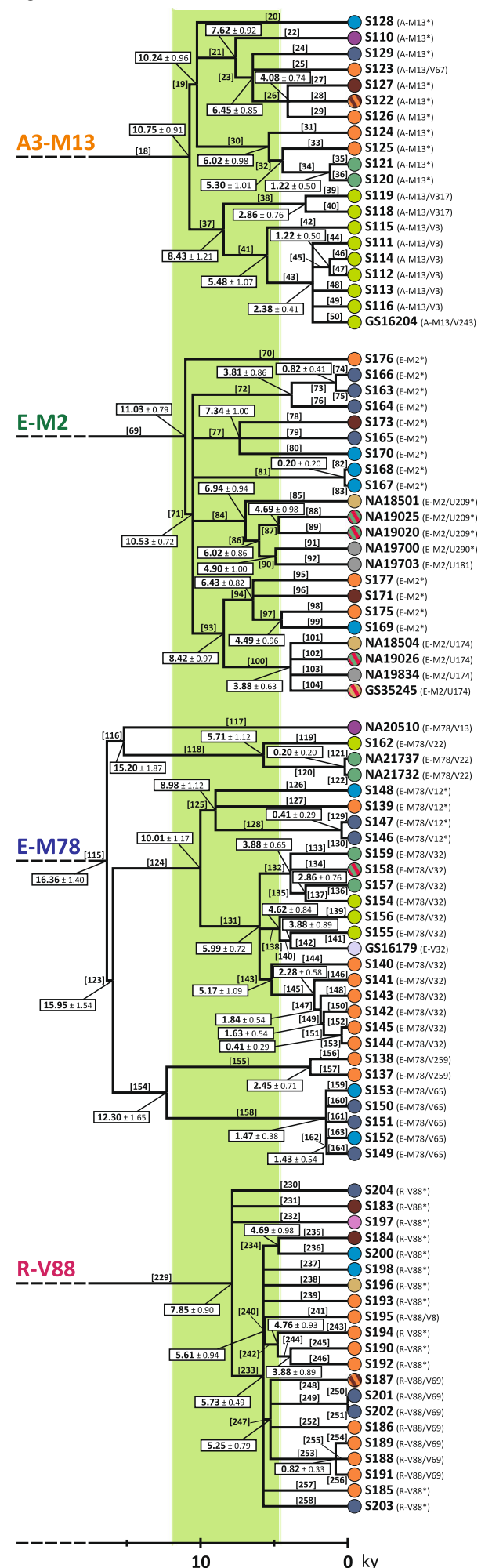

Fig. 2 (See legend on next page.) 
(See figure on previous page.)

Fig. 2 Maximum parsimony $Y$ chromosome tree and dating of the four trans-Saharan haplogroups. a Phylogenetic relations among the 150 samples analysed here. Each haplogroup is labelled in a different colour. The four $Y$ sequences from ancient samples are marked by the dagger symbol. b Phylogenetic tree of the four trans-Saharan haplogroups, aligned to the timeline (at the bottom). At the tip of each lineage, the ethno-geographic affiliation of the corresponding sample is represented by a circle, coloured according to the legend (bottom left). The last Green Sahara period is highlighted by a green belt in the background

\section{Population analysis of the four trans-Saharan clades}

In order to gain more information about the ethnogeographic distribution of the four trans-Saharan haplogroups (Fig. 3), we selected 142 informative markers (Additional file 1: Table S4) belonging to these lineages and analysed them in a wider sample composed of 7955 males from 145 worldwide populations (128 from our lab collection and 17 from the literature) (Fig. 4) $[51,53]$ (Additional file 1: Table S5). It is worth noting that 96 ethnic groups come from different African regions, allowing us to obtain a detailed picture of the genetic variability of the four haplogroups across the Sahara (Figs. 3 and 4).

We also included eight admixed populations from America [51], whose genetic variation has been shaped by the trans-Atlantic slave trade (XV-XIX centuries), to be used as a "positive control" to investigate the effects of other recent historical events, such as the Arab slave trade (VII-XIX centuries) which involved the forced movement of millions of sub-Saharan Africans toward northern Africa [54] (see "Discussion").

The genotyping results for A3-M13 confirmed its very high geographic differentiation, with most lineages restricted to one geographic area. There are few exceptions to this general pattern, i.e. A3-V2742*, A3-V2816* and A3-V3800, which were found in two different regions, usually belonging to the same geographical macro-area (Additional file 2: Figure S3). While A3-V1018 is restricted to the Horn of Africa, its sister clade, A3-V5912, is more widespread, arriving as far as southern Europe (more specifically, Sardinia) (Additional file 1: Table S5). Most of the Mediterranean lineages coalesced with subSaharan clades in a time window between 10.24 and 6.45 kya (where the upper and lower limit are the coalescence ages of A3-V5912 and A3-V2336, respectively) (Fig. 3b), during the last humid phase of the Sahara (12-5 kya). After this period, the lineages are restricted to sub-Saharan Africa or northern Africa. It is worth noting that A3-V4735 has been found both in central Sahel and in the Great Lakes region (Kenya and Uganda) in eastern Africa, suggesting a movement along the Sahelian belt starting during the final period of the last Green Sahara (6.02-5.30 kya).

It is known that the geographic distribution of E-M2 in sub-Saharan Africa has been heavily influenced by the recent (<3 kya) Bantu expansion [11-17] and this is mirrored by the high frequencies of several E-M2 sub- clades among the Bantu people, in particular E-U290 and E-U174 (Additional file 1: Table S5 and Additional file 2: Figure S4). However, we found clues as to the role of the last Green Sahara considering the phylogeography of the E-M2 sub-clades in northern Africa. The coalescence age of the lineages harbouring northern and subSaharan chromosomes predates the onset of the arid conditions, falling between 11.03 kya (coalescence age of E-Page66) and 4.49 kya (the time estimate of the most recent clade harbouring a relevant proportion of northern African samples, i.e. E-V5280), during the last Green Sahara. After this time frame, we observed clades restricted to the north or to the south of the Sahara. In this context, although the large majority of the geographically restricted lineages come from sub-Saharan regions, we also found two northern African-specific clades, namely E-V5001 and E-V4990. E-V5001 has only been found in Egypt, is one of the sister clades within the E-M4727 multifurcation and coalesced at 3.88 kya. E-V4990 is a Moroccan clade dated to < 4.49 kya (the time estimate of the upstream node). Interestingly, it is the terminal branch of a nested topology, which divides western Africa from Morocco. We found a relevant proportion ( $22 \%$ ) of African-American subjects belonging to the E-M2 haplogroup (Additional file 1: Table S5). These groups have been heavily influenced by the Atlantic slave trade, which took place between the XV and XIX centuries and of which the source populations were mainly sub-Saharan people. Consistent with the autosomal data [55], these subjects have been found to be very similar to the source African populations in their E-M2 sub-haplogroup composition (Additional file 2: Figure S4).

The distribution and age estimates of different E-M78 sub-haplogroups show a strong parallelism. Excluding the E-V13 subclade, which has been linked to the Neolithic transition in the Near East [34], all the other three major E-M78 lineages (E-V264, E-V22 and E-V12) include a Mediterranean clade (harbouring northern African, near-eastern and southern European samples) and a sub-Saharan clade (Fig. 3b; Additional file 2: Figure S5). The age estimates of the nodes joining the lineages from these two macro-areas are quite concordant (12.30 kya for E-V264, 11.01 kya for E-V22 and 10.01 kya for E-V12) and correspond to the beginning of the humid phase in the eastern Sahara, where E-M78 probably originated [34, 35]. After the end of the last 
Table 1 Time estimates for the nodes of the phylogenetic tree

\begin{tabular}{llllll}
\hline Haplogroup & Node & Rho & SD Rho & Time (kya) & SD time (kya) \\
\hline- & Root & 628.78 & 20.46 & 256.54 & 8.35
\end{tabular}

$\begin{array}{llllll}\text { A0'T } & 1 & 420.48 & 14.81 & 171.55 & 6.04 \\ \text { A0 } & 2 & 29.00 & 3.81 & 11.83 & 1.55 \\ \text { A1'T } & 5 & 359.57 & 12.71 & 146.71 & 5.19 \\ \text { A2'T } & 7 & 348.91 & 12.36 & 142.35 & 5.94\end{array}$

$\begin{array}{llllll}\text { A2'3 } & 8 & 310.72 & 14.64 & 126.77 & 5.97\end{array}$

$\begin{array}{llllll}\text { A2-PN3 } & 9 & 71.50 & 5.98 & 29.17 & 2.44\end{array}$

$\begin{array}{llllll}\text { A3-M32 } & 12 & 224.09 & 12.89 & 91.43 & 5.26\end{array}$

$\begin{array}{llllll}\text { A3-M144 } & 14 & 144.18 & 10.06 & 58.83 & 4.10\end{array}$

$\begin{array}{llllll}\text { A3-M51 } & 15 & 50.50 & 5.02 & 20.60 & 2.05\end{array}$

$\begin{array}{llllll}\text { A3-M13 } & 18 & 26.35 & 2.23 & 10.75 & 0.91\end{array}$

$\begin{array}{llllll}\text { A3-M13 } & 19 & 25.09 & 2.36 & 10.24 & 0.96\end{array}$

$\begin{array}{llllll}\text { A3-M13 } & 21 & 18.67 & 2.25 & 7.62 & 0.92\end{array}$

$\begin{array}{llllll}\text { A3-M13 } & 23 & 15.80 & 2.09 & 6.45 & 0.85\end{array}$

$\begin{array}{llllll}\text { A3-M13 } & 26 & 10.00 & 1.83 & 4.08 & 0.74\end{array}$

$\begin{array}{llllll}\text { A3-M13 } & 30 & 14.75 & 2.41 & 6.02 & 0.98\end{array}$

$\begin{array}{llllll}\text { A3-M13 } & 32 & 13.00 & 2.47 & 5.30 & 1.01\end{array}$

$\begin{array}{llllll}\text { A3-M13 } & 34 & 3.00 & 1.22 & 1.22 & 0.50\end{array}$

$\begin{array}{llllll}\text { A3-M13 } & 37 & 20.67 & 2.97 & 8.43 & 1.21\end{array}$

$\begin{array}{llllll}\text { A3-M13 } & 38 & 7.00 & 1.87 & 2.86 & 0.76\end{array}$

$\begin{array}{llllll}\text { A3-M13 } & 41 & 13.43 & 2.62 & 5.48 & 1.07\end{array}$

$\begin{array}{llllll}\text { A3-M13 } & 43 & 5.83 & 1.01 & 2.38 & 0.41\end{array}$

$\begin{array}{llllll}\text { A3-M13 } & 45 & 3.00 & 1.22 & 1.22 & 0.50\end{array}$

$\begin{array}{llllll}\text { B'T } & 51 & 238.79 & 9.90 & 97.42 & 4.04\end{array}$

$\begin{array}{llllll}\text { B } & 52 & 222.00 & 9.39 & 90.58 & 3.83\end{array}$

$\begin{array}{llllll}\text { B-M236 } & 53 & 32.00 & 4.00 & 13.06 & 1.63\end{array}$

$\begin{array}{llllll}\text { B-M182 } & 56 & 150.00 & 8.96 & 61.20 & 3.65\end{array}$

$\begin{array}{llllll}\text { B-M150 } & 57 & 8.00 & 2.00 & 3.26 & 0.82\end{array}$

$\begin{array}{llllll}\text { D'T } & 61 & 180.13 & 6.91 & 73.49 & 2.82\end{array}$

$\begin{array}{llllll}\text { DE-YAP } & 62 & 175.36 & 9.70 & 71.55 & 3.96\end{array}$

$\begin{array}{llllll}\text { E-M40 } & 64 & 142.39 & 8.03 & 58.09 & 3.28\end{array}$

$\begin{array}{llllll}E-P 110 & 66 & 139.48 & 7.98 & 56.91 & 3.26\end{array}$

$\begin{array}{llllll}E-P 2 & 68 & 118.87 & 6.71 & 48.50 & 2.74\end{array}$

$\begin{array}{llllll}\text { E-M2 } & 69 & 27.05 & 1.95 & 11.03 & 0.79\end{array}$

$\begin{array}{llllll}\text { E-M2 } & 71 & 25.81 & 1.76 & 10.53 & 0.72\end{array}$

$\begin{array}{llllll}\text { E-M2 } & 72 & 9.33 & 2.11 & 3.81 & 0.86\end{array}$

$\begin{array}{llllll}\text { E-M2 } & 73 & 2.00 & 1.00 & 0.82 & 0.41\end{array}$

$\begin{array}{llllll}\text { E-M2 } & 77 & 18.00 & 2.45 & 7.34 & 1.00\end{array}$

$\begin{array}{llllll}\text { E-M2 } & 81 & 0.50 & 0.50 & 0.20 & 0.20\end{array}$

$\begin{array}{llllll}\text { E-M2 } & 84 & 17.00 & 2.31 & 6.94 & 0.94\end{array}$

$\begin{array}{llllll}\text { E-M2 } & 86 & 14.75 & 2.11 & 6.02 & 0.86\end{array}$

$\begin{array}{llllll}\text { E-M2 } & 87 & 11.50 & 2.40 & 4.69 & 0.98\end{array}$

$\begin{array}{llllll}\text { E-M2 } & 90 & 12.00 & 2.45 & 4.90 & 1.00\end{array}$

$\begin{array}{llllll}\text { E-M2 } & 93 & 20.63 & 2.37 & 8.42 & 0.97\end{array}$
Table 1 Time estimates for the nodes of the phylogenetic tree (Continued)

\begin{tabular}{|c|c|c|c|c|c|}
\hline Haplogroup & Node & Rho & SD Rho & Time (kya) & SD time (kya) \\
\hline E-M2 & 94 & 15.75 & 2.02 & 6.43 & 0.82 \\
\hline E-M2 & 97 & 11.00 & 2.35 & 4.49 & 0.96 \\
\hline E-M2 & 100 & 9.50 & 1.54 & 3.88 & 0.63 \\
\hline E-M35 & 105 & 69.10 & 5.63 & 28.19 & 2.30 \\
\hline E-M35 & 106 & 62.00 & 5.03 & 25.30 & 2.05 \\
\hline E-M35 & 107 & 40.50 & 4.50 & 16.52 & 1.84 \\
\hline E-V68 & 111 & 57.70 & 5.11 & 23.54 & 2.08 \\
\hline E-V68 & 112 & 9.00 & 2.12 & 3.67 & 0.87 \\
\hline E-M78 & 115 & 40.11 & 3.42 & 16.36 & 1.40 \\
\hline E-M78 & 116 & 37.25 & 4.59 & 15.20 & 1.87 \\
\hline E-M78 & 118 & 14.00 & 2.75 & 5.71 & 1.12 \\
\hline E-M78 & 120 & 0.50 & 0.50 & 0.20 & 0.20 \\
\hline E-M78 & 123 & 39.08 & 3.78 & 15.95 & 1.54 \\
\hline E-M78 & 124 & 24.53 & 2.86 & 10.01 & 1.17 \\
\hline E-M78 & 125 & 22.00 & 2.74 & 8.98 & 1.12 \\
\hline E-M78 & 128 & 1.00 & 0.71 & 0.41 & 0.29 \\
\hline E-M78 & 131 & 14.69 & 1.76 & 5.99 & 0.72 \\
\hline E-M78 & 132 & 9.50 & 1.58 & 3.88 & 0.65 \\
\hline E-M78 & 135 & 7.00 & 1.87 & 2.86 & 0.76 \\
\hline E-M78 & 138 & 11.33 & 2.05 & 4.62 & 0.84 \\
\hline E-M78 & 140 & 9.50 & 2.18 & 3.88 & 0.89 \\
\hline E-M78 & 143 & 12.67 & 2.68 & 5.17 & 1.09 \\
\hline E-M78 & 145 & 5.60 & 1.41 & 2.28 & 0.58 \\
\hline E-M78 & 147 & 4.50 & 1.32 & 1.84 & 0.54 \\
\hline E-M78 & 149 & 4.00 & 1.33 & 1.63 & 0.54 \\
\hline E-M78 & 151 & 1.00 & 0.71 & 0.41 & 0.29 \\
\hline E-M78 & 154 & 30.14 & 4.04 & 12.30 & 1.65 \\
\hline E-M78 & 155 & 6.00 & 1.73 & 2.45 & 0.71 \\
\hline E-M78 & 158 & 3.60 & 0.94 & 1.47 & 0.38 \\
\hline E-M78 & 162 & 3.50 & 1.32 & 1.43 & 0.54 \\
\hline$C^{\prime} T$ & 165 & 175.74 & 9.32 & 71.70 & 3.80 \\
\hline C & 166 & 118.00 & 7.68 & 48.14 & 3.13 \\
\hline G'T & 169 & 124.54 & 6.52 & 50.81 & 2.66 \\
\hline I'T & 171 & 122.35 & 6.49 & 49.92 & 2.65 \\
\hline IJ & 172 & 106.89 & 7.37 & 43.61 & 3.01 \\
\hline I & 173 & 12.33 & 2.13 & 5.03 & 0.87 \\
\hline I-M253 & 176 & 11.50 & 2.40 & 4.69 & 0.98 \\
\hline J & 182 & 76.38 & 6.68 & 31.16 & 2.73 \\
\hline J-M267 & 183 & 43.07 & 4.19 & 17.57 & 1.71 \\
\hline J-M267 & 184 & 11.00 & 2.35 & 4.49 & 0.96 \\
\hline J-M267 & 187 & 42.08 & 4.64 & 17.17 & 1.89 \\
\hline J-M267 & 188 & 28.83 & 3.45 & 11.76 & 1.41 \\
\hline J-M267 & 189 & 17.78 & 2.44 & 7.25 & 1.00 \\
\hline
\end{tabular}


Table 1 Time estimates for the nodes of the phylogenetic tree (Continued)

\begin{tabular}{llllll}
\hline Haplogroup & Node & Rho & SD Rho & Time (kya) & SD time (kya) \\
\hline J-M267 & 191 & 12.75 & 1.51 & 5.20 & 0.62 \\
J-M267 & 193 & 11.00 & 1.27 & 4.49 & 0.52 \\
J-M267 & 198 & 9.00 & 2.12 & 3.67 & 0.87 \\
J-M267 & 202 & 5.00 & 1.29 & 2.04 & 0.53 \\
K & 210 & 116.81 & 8.74 & 47.66 & 3.57 \\
Q'R & 214 & 88.77 & 7.30 & 36.22 & 2.98 \\
R & 216 & 72.30 & 6.31 & 29.50 & 2.57 \\
R-M173 & 217 & 56.79 & 5.25 & 23.17 & 2.14 \\
R-M420 & 218 & 8.00 & 2.00 & 3.26 & 0.82 \\
R-V1501 & 221 & 45.78 & 4.52 & 18.68 & 1.85 \\
R-P312/U152 & 222 & 13.67 & 1.51 & 5.58 & 0.62 \\
R-V88 & 229 & 19.24 & 2.20 & 7.85 & 0.90 \\
R-V88 & 233 & 14.06 & 1.19 & 5.73 & 0.49 \\
R-V88 & 234 & 11.50 & 2.40 & 4.69 & 0.98 \\
R-V88 & 240 & 13.75 & 2.30 & 5.61 & 0.94 \\
R-V88 & 242 & 11.67 & 2.29 & 4.76 & 0.93 \\
R-V88 & 244 & 9.50 & 2.18 & 3.88 & 0.89 \\
R-V88 & 247 & 12.86 & 1.95 & 5.25 & 0.79 \\
R-V88 & 253 & 2.00 & 0.82 & 0.82 & 0.33 \\
\hline For ench no & we & \\
\hline
\end{tabular}

For each node, we report Haplogroup, node number (Fig. 2), Rho statistics, time estimate in thousands of years ago (kya) and their standard deviation (SD)

Green Sahara ( $\sim \mathrm{kya})$, the differentiation is sharp, with no lineages including both Mediterranean and subSaharan subjects. The sub-Saharan clades E-V264/V259 and E-V22/V3262 are restricted to central Sahel and eastern Africa (mainly the Horn of Africa), respectively, whereas E-V12/V32 is very frequent in eastern Africa but it also includes a central Sahelian clade, suggesting a Sahelian movement between 5.99 and 5.17 kya.

The genotyping of R-V88 internal markers disclosed the phylogenetic relationships of two rare European sub-clades (R-M18 and R-V35) with respect to Africanspecific clades (Additional file 2: Figure S6). The presence of two nested R-V88 basal European clades can be related to the high frequencies of R-V88 internal lineages in the central Sahel assuming a movement from Europe toward the central Sahel across northern Africa. In turn, considering the trans-Saharan distribution and the "star-like" topology of the sub-clade R-V1589 (branch 233), it is likely that this lineage rapidly expanded in the lake Chad area between 5.73 and 5.25 kya and moved backward to northeastern Africa across the Saharan region (Fig. 3b; Additional file 2: Figure S6). The large majority of R-V1589 internal lineages harbours both northern and central Sahelian subjects, with the exception of R-V4759 and R-V5781, which are mainly restricted to northern Africa and central Sahel, respectively (Additional file 1: Table S5). The presence of a precisely dated and geographically restricted clade (R-V4759 in northern Africa; Additional file 1: Table S5 and Additional file 2: Figure S6) allowed us to define its coalescence age (4.69 kya) as the lower limit for the backward R-V88 trans-Saharan movement.

\section{Beyond the last Green Sahara}

Although the focus of the present study was to understand the African population dynamics linked to the last Green Sahara period, we also found evidence of other movements within and outside Africa involving different ethnic groups and that occurred before or after the Holocene climatic optimum.

The Sahelian belt spans from the Atlantic Ocean to the Red Sea, immediately south of the Sahara. Its climate and ecology are intermediate between desert (typical of the Sahara to the north) and the tropical savannah (typical of the regions to the south). In this area, several languages belonging to three of the four African linguistic families (i.e. Afro-asiatic, Nilo-Saharan and NigerCongo) are spoken, confirming that the Sahel has been an important crossroad in the African continent. We found evidence of Sahelian movements in at least three haplogroups: A3-M13/V4735, E-M2/Z15939 and EM78/V32 (Additional file 2: Figures S2-S4). A3-M13/ V4735 and E-M78/V32 seem to have been involved in human movements that occurred in the same time window ( 6-5 kya) along the same bi-directional Sahelian axis from lake Chad to eastern Africa. A3-M13/V4735 probably originated somewhere in the central Sahel between 10.24 and 6.02 kya and possibly arrived in eastern Africa after $6.02 \mathrm{kya}$. This clade is significantly related to the Nilo-Saharan speaking groups (Mann-Whitney test, $\left.p=2.82 \times 10^{-4}\right)$, refining previous hypotheses about the association between A3-M13 and the Nilo-Saharan spread from central Sahel to eastern Africa $[14,18]$. In the same period, we found evidence of a movement along the same Sahelian axis involving the internal lineages of E-M78/V32. This haplogroup probably differentiated in eastern Africa 5.99 kya, and we observed a shift in its geographic distribution towards the central Sahel, where it arrived not later than 5.17 kya. Interestingly, all the central sahelian E-V32 chromosomes belong to the internal clade E-V32/V6873, which is almost exclusively found among the Nilo-Saharans (Mann-Whitney test, $p=0.01)$. These findings suggest that the NiloSaharan spread along the Sahelian belt was probably a complex event, involving different clades and different movements from the lake Chad basin to eastern Africa and back. Haplogroup E-M2/Z15939, whose coalescence age $(\sim 7 \mathrm{kya})$ falls within the last Green Sahara period, seems to have been involved in another 


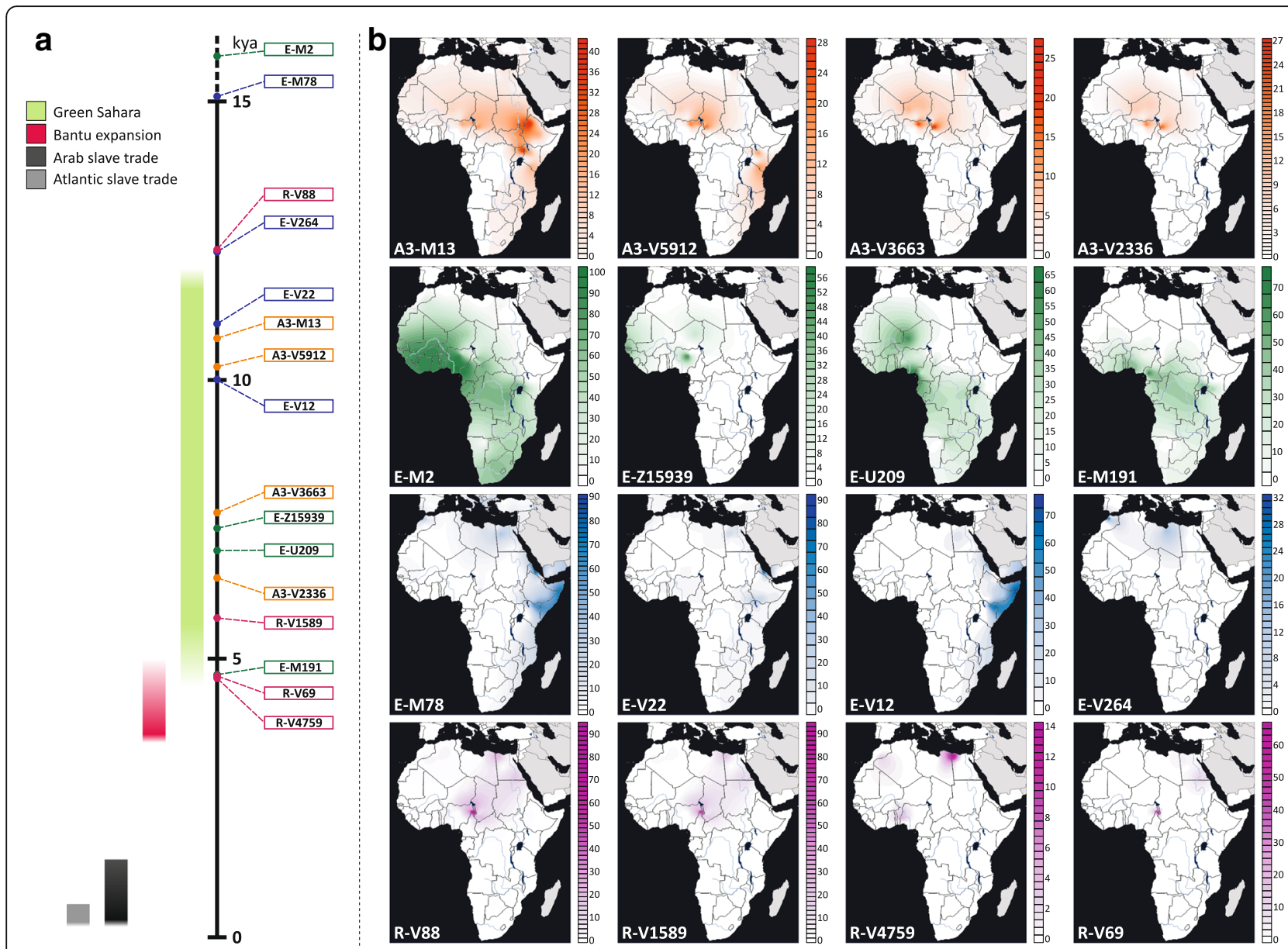

Fig. 3 Time estimates and frequency maps of the four trans-Saharan haplogroups and major sub-clades. a Time estimates of the four trans-Saharan clades and their main internal lineages. To the left of the timeline, the time windows of the main climatic/historical African events are reported in different colours (legend in the upper left). b Frequency maps of the main trans-Saharan clades and sub-clades. For each map, the relative frequencies (percentages) are reported to the right

Sahelian movement, being present at high frequencies among different Fulbe groups. Interestingly, the geographic distribution of this clade (Fig. 3b) perfectly traces the Fulbe migration from western Africa, where this haplogroup is also common in other ethnic groups, to central Sahel, where the same haplogroup is only found among Fulbe populations.

Outside Africa, both A3-M13 and R-V88 harbour sub-lineages geographically restricted to the island of Sardinia and both seem to indicate ancient transMediterranean contacts. The phylogeography of A3M13 suggests that the direction of the movement was from Africa to Sardinia, while R-V88 topology indicates a Europe-to-Africa migration. Indeed, our data suggest a European origin of R-V88 about 12.3 kya, considering both the presence of two Sardinian R-V88 basal clades (R-M18 and R-V35) and that the V88 marker arose in the R-M343 background, which in turn includes Near-Eastern/European lineages [52]. It is worth noting that the arrival of R-V88 in the Sahara seems to have occurred between 8.67 and 7.85 kya (considering as an upper limit the time estimates of the last node including a European-specific lineage, while the lower limit is the coalescence age of all the African-specific lineages), refining the time frame of the trans-Saharan migration proposed in previous studies $[37,56]$. The route of R-V88 toward the lake Chad basin probably passed through northeastern Africa rather than Arabia, considering the absence of R-V88 in the Horn of Africa. Interestingly, both A3M13 and R-V88 European sub-clades coalesced in ancient times (> 7.62 kya for A3-M13/V2742 and between 12.34 and 8.67 kya for R-V88/M18 and R-V88/V35) (Additional file 2: Figures S2 and S5). So it is possible that both clades were widespread in southern Europe, where they have been replaced by the Y haplogroups brought by the following recurrent migration waves from Asia [57]. 


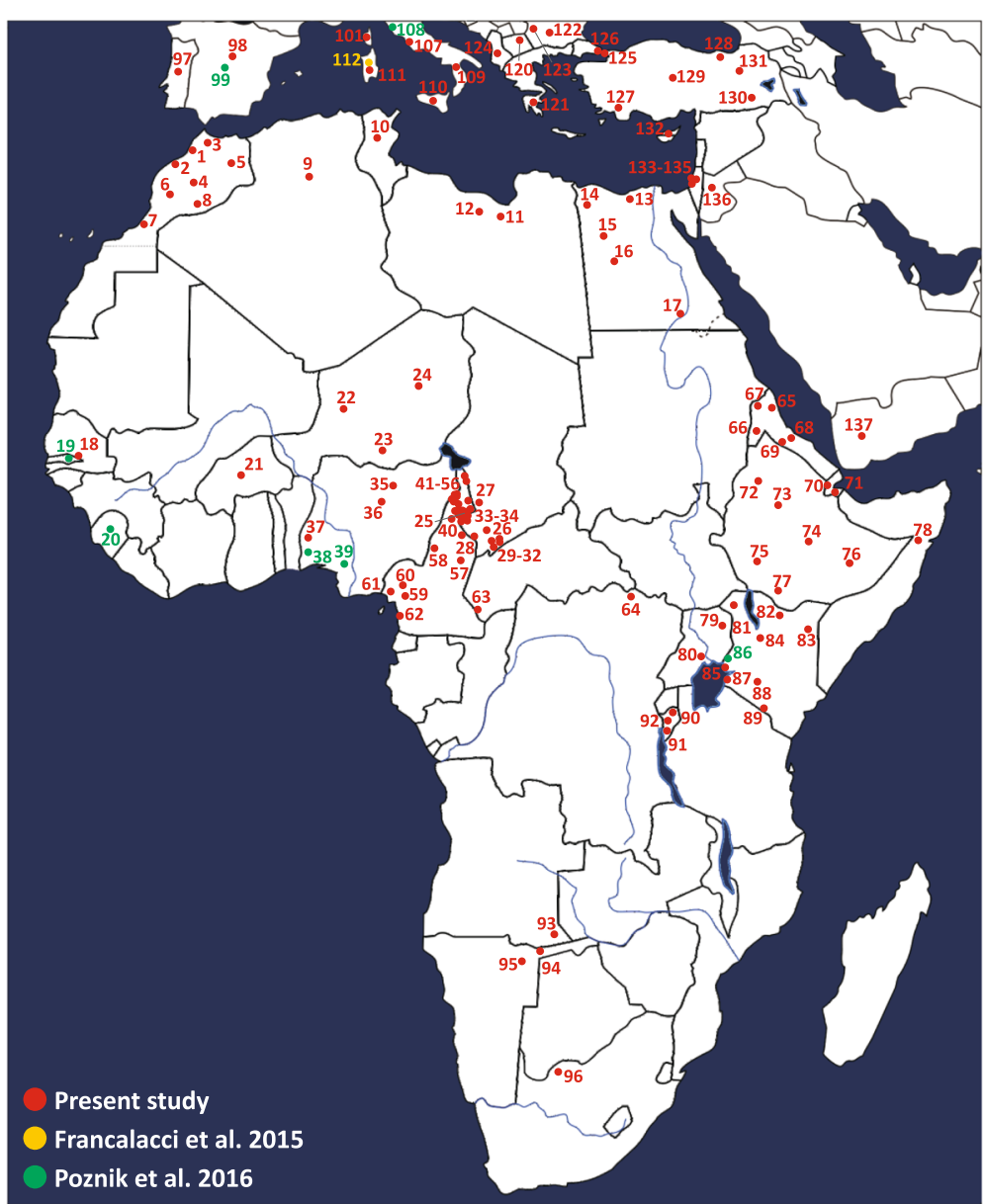

Fig. 4 Map of the populations analysed. Geographic positions of the populations from Africa, southern Europe and Near East are shown. For population labels refer to Additional file 1: Table S5

\section{Discussion}

\section{Role of the Green Sahara in the distribution of the four haplogroups}

The large majority of nodes joining northern and subSaharan patrilineages date back to the Green Sahara period. On the contrary, most clades geographically restricted to one of these two macro-regions coalesced after 5 kya. Usually, the presence of a sub-Saharan genetic component in northern Africa is put down to the Arab slave trade (VII-XIX centuries) from the subSaharan regions towards the markets located along the Mediterranean coast [42-44]. If this was the case, we should observe no significant differences in the subSaharan component of $\mathrm{Y}$ haplogroups between the African American and northern African populations, since both the Atlantic and the Arab slave trade are recent events, which involved the same source geographic area (Fig. 3a). However, considering the distribution of E-M2 sub-lineages in the American admixed, northern African and sub-Saharan populations (Fig. 5), we found a significant correlation between admixed and sub-
Saharan groups (Spearman's Rho $=0.687, p=3.76 \times 10^{-6}$ ) consistent with the genome-wide data $[55,58]$, while northern Africans and sub-Saharan people were not correlated (Spearman's Rho $=0.07, p=0.68$ ). Consistent with these findings, also northern Africans and American admixed people were found not to be correlated (Spearman's Rho $=0.22, p=0.19$ ).

The same pattern was also observed when only the western-central Sahelian groups of sub-Saharan Africa were considered (admixed vs. western-central Sahel, Spearman's Rho $=0.509, p=1.51 \times 10^{-3}$; northern Africa $v s$ western-central Sahel, Spearman's Rho $=0.218$, $p=0.2$ ). These data suggest that the presence in northern Africa of sub-Saharan patrilineages was not due to recent contacts but probably occurred in more ancient times, possibly during the Green Sahara period considering the coalescence ages of the clades. Our findings seem to be at odds with genome-wide studies $[42,43,59,60]$ reporting a recent relevant sub-Saharan genetic component in modern northern African populations, mainly attributed to the Arab slave trade. This apparent 


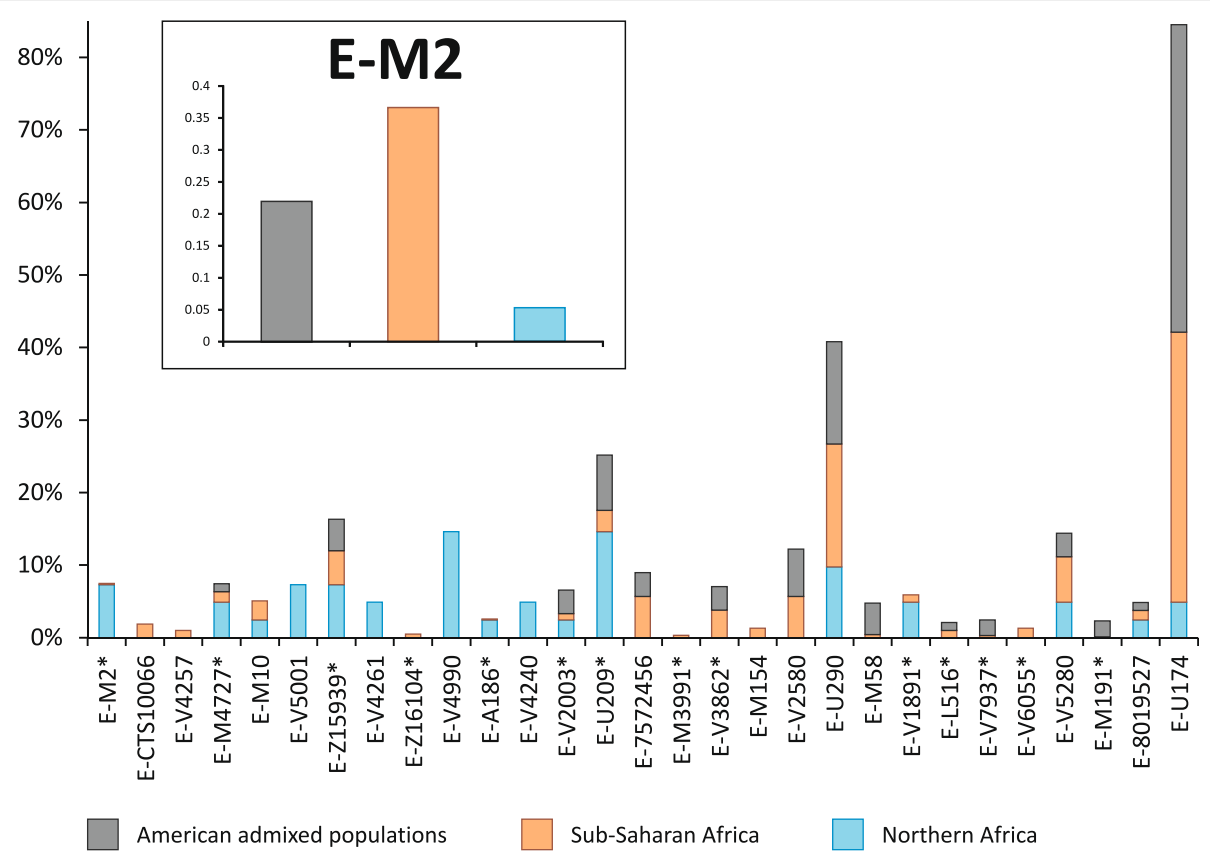

Fig. 5 Relative proportions of American admixed, sub-Saharan or northern African Y chromosomes belonging to the E-M2 sub-clades. Data from the nomadic populations (Tuareg and Fulbe) and from seven lineages with an absolute frequency equal to 1 were not used for the generation of this graph. Compared to the macroregion sub-division reported in Additional file 1: Table S5, we collapsed "Northeastern Africa" and "Northwestern Africa" macroregions into "Northern Africa", while the "Sub-Saharan Africa" group includes "Central Sahel", "Western Africa", "Central Africa", "Great Lakes region", "Horn of Africa", "Southern Africa" and all the Bantu groups in these regions. In the inset, we report the relative frequencies of the whole E-M2 haplogroup in the same macroregions

discrepancy between inferences based on Y chromosomal and autosomal data could be the consequence of a sexbiased sub-Saharan contribution to the northern African gene pool that occurred in historical times. Indeed, it is known that the trans-Saharan Arab slave trade involved twice as many servile women as men (almost the reverse of the Atlantic slave trade ratio). Moreover, few male slaves left descendants, whereas female slaves were imported in northern Africa as household servants and as concubines and their offspring were born free, thus contributing to the local gene pool $[54,61]$. Thus, we suggest that the Arab slave trade mainly contributed to the mtDNA and autosomal gene pool of present-day northern Africans, whereas the paternal gene pool was mainly shaped by more ancient events. This hypothesis is in line with genome-wide data obtained from three ancient Egyptian mummies (dated between $\sim 2.5$ and 2 kya) showing a not negligible ancient sub-Saharan component $(\sim 6-10 \%)$ [44].

Considering the data for all the four trans-Saharan haplogroups reported here, we can try to paint a comprehensive picture of the events during the last African humid period. The first occupation of the Sahara may have occurred from both northern and southern regions, following the spread of the fertile environment and according with the two-way occupation of the Green
Sahara proposed on the basis of paleoanthropological evidence [2]. The topology and geographic distribution (Additional file 2: Figures S3 and S4) of both A3-M13 and E-M2 suggest that these lineages were brought to the Sahara from the southern regions, while E-M78 and R-V88 seem to have followed the opposite route.

The fertile environment established in the Green Sahara probably promoted demographic expansions and rapid dispersals of the human groups, as suggested by the great homogeneity in the material culture of the early Holocene Saharan populations [62]. Our data for all the four trans-Saharan haplogroups are consistent with this scenario, since we found several multifurcated topologies, which can be considered as phylogenetic footprints of demographic expansions. The multifurcated structure of the E-M2 is suggestive of a first demographic expansion, which occurred about $10.5 \mathrm{kya}$, at the beginning of the last Green Sahara (Fig. 2; Additional file 2: Figure S4). After this initial expansion, we found that most of the trans-Saharan lineages within A3-M13, E-M2 and R-V88 radiated in a narrow time interval at 8-7 kya, suggestive of population expansions that may have occurred in the same time (Fig. 2; Additional file 2: Figures S3, S4 and S6). Interestingly, during roughly the same period, the Saharan populations adopted pastoralism, probably as an adaptive strategy 
against a short arid period [1, 62, 63]. So, the exploitation of pastoralism resources and the reestablishment of wetter conditions could have triggered the simultaneous population expansions observed here. R-V88 also shows signals of a further and more recent ( $5.5 \mathrm{kya})$ Saharan demographic expansion which involved the RV1589 internal clade. We observed similar demographic patterns in all the other haplogroups in about the same period and in different geographic areas (A3-M13/V3, EM2/V3862 and E-M78/V32 in the Horn of Africa, EM2/M191 in the central Sahel/central Africa), in line with the hypothesis that the start of the desertification may have caused massive economic, demographic and social changes [1].

Finally, the onset of the arid conditions at the end of the last African humid period was more abrupt in the eastern Sahara compared to the central Sahara, where an extensive hydrogeological network buffered the climatic changes, which were not complete before $\sim 4$ kya $[6,62,64]$. Consistent with these local climatic differences, we observed slight differences among the four trans-Saharan haplogroups. Indeed, we found that the contact between northern and sub-Saharan Africa went on until $\sim 4.5$ kya in the central Sahara, where we mainly found the internal lineages of E-M2 and R-V88 (Additional file 2: Figures S4 and S6). In the eastern Sahara, we found a sharper and more ancient (> 5 kya) differentiation between the people from northern Africa (and, more generally, from the Mediterranean area) and the groups from the eastern sub-Saharan regions (mainly from the Horn of Africa), as testified by the distribution and the coalescence ages of the A3-M13 and E-M78 lineages (Additional file 2: Figures S3 and S5).

\section{Conclusions}

Our data suggest that the favourable climatic conditions and the fertile environment established in the Sahara during the last African humid period promoted the occupation and dispersal of human groups and contributed to the present distribution of $Y$ lineages in northern and sub-Saharan Africa. On the contrary, historical events, such as the Arab slave trade, had only a marginal role in the Y genetic composition of African people. Our inferences are based on the assumption that migration events that occurred in recent times are reflected by recent coalescence times of $\mathrm{Y}$ lineages. To support our assumption, we included in this study a large number of African, European and near-eastern ethnic groups (both from our lab collection and from the literature data) in order to consider as much genetic diversity as possible. However, we could not completely exclude the presence of informative haplogroups in other populations/regions absent in our sample collection. More sample efforts could lead to the identification of other informative data from other populations and these findings could refine our inferences. Nonetheless, this study highlights the importance of the targeted selection and analysis of uniparental haplogroups with a relic distribution to understand past human history, which could be concealed by the genetic changes caused by successive events.

\section{Methods}

\section{The sample}

We performed targeted NGS on 104 subjects from our lab collection selected on the basis of their haplogroup affiliation [19, 22, 33-35, 37, 52, 65], focusing on the four trans-Saharan haplogroups A3-M13, E-M2, E-M78 and R-V88. In order to increase the power of resolution of the study, from the literature we also added $42 \mathrm{Y}$ chromosomes sequenced at high-coverage [45, 48]. Finally, we included four radiocarbon-dated ancient specimens $[46,47,49]$ to be used as calibration points for the time estimates, for a total of 150 subjects (Additional file 1: Table S1). We also selected 142 informative markers to genotype more than 6000 men belonging to 128 populations (see below).

\section{DNA quality control}

The 104 DNA samples from our lab collection were obtained from peripheral blood, saliva or cultured cells. Target sequencing required specific quality and quantity parameters for the DNA to be analysed: 1) absence or low amount of DNA degradation; 2) quantity $\geq 3 \mu \mathrm{g}$; 3 ) concentration $\geq 37.5 \mathrm{ng} / \mu \mathrm{l}$; 4) purity, A260/280 $=1.8-2.0$. Concentration and purity were measured using a NanoDrop 1000 spectrophotometer, produced by Thermo Fisher Scientific. Degradation was assessed by means of an electrophoretic run on a $1 \%$ agarose gel. We performed a whole genome amplification (WGA) of 59 samples with an insufficient quantity of DNA, using the GenomiPhi V2 DNA Amplification kit (GE Healthcare) according to the manufacturer's protocol.

\section{Selection of the unique MSY regions to be sequenced}

We selected 22 blocks within the X-degenerate portion of the Y chromosome [66] (Fig. 1; Additional file 1: Table S6), for a total of about $11 \mathrm{Mb}$ which were characterized by a low degree of homology with the $\mathrm{X}$ chromosome or with the autosomes $[67,68]$. The total number of targeted bases decreased to about $4 \mathrm{Mb}$ after the exclusion of the repetitive elements [69]. For these selection steps, we used the "Table browser" tool of the UCSC Genome browser, considering the aligned annotation tracks for the human February 2009 (GRCh37/hg19) assembly.

\section{Targeted NGS}

Library preparation, targeting, sequencing and alignment were performed by BGI-Tech (Hong Kong). The targeted 
unique regions of the MSY were captured using a Roche Nimblegen custom capture array, composed of a set of 200 -bp probes. The probes excluded almost all the repetitive elements from the $22 \mathrm{X}$-degenerated blocks, capturing a total of about 4.4 $\mathrm{Mb}$. The captured regions were loaded onto an Illumina HiSeq 2500 platform to produce a $>50 \times$ mean depth for the targeted 4.4 Mb.

The low quality reads, contamination with adapters and repeated reads were discarded and the sequences of each subject aligned to the human $Y$ chromosome reference sequence (GRCh37/hg19) by means of the BWA (Burrows-Wheeler Aligner) software [70], generating an alignment file (.bam format) [71, 72].

\section{Selection of the final set of reliable bases}

In order to discard problematic regions (involved in rearrangements, deletions, duplication, etc.) and to obtain a reliable set of bases for the SNP calling in all 104 subjects, we performed an analysis of depth through the extraction of some informative values from each bam file using the SAMtools platform [71, 73] (Additional file 3: Supplementary Text). In this way, we obtained a final set of $\sim 3.3 \mathrm{Mb}$, which were used for all the subsequent analysis (Additional file 1: Table S7).

\section{SNP calling and filtering}

The variant positions were extracted using the SAMtools platform $[71,73]$ by comparing our 104 sequences to the human Y chromosome reference sequence (February 2009, GRCh37/hg19 assembly). The output was in the form of a VCF (Variant Call Format) file for each sample. The same process was performed for the $\mathrm{Y}$ chromosome of the ancient samples [46, 47, 49]. On the contrary, for the 42 modern public subjects from Complete Genomics [45] and Karmin and colleagues [48], we extracted the variant positions within the final $\sim 3.3 \mathrm{Mb}$ directly from publicly available VCF files.

In order to discard false positive calls, we applied different filtering criteria, which can be grouped into three different categories: 1) direct filtering-we used the information embedded in the VCF file to accept or discard the variant positions; 2) manual filtering-we manually checked the uncertain cases from the previous filtering step in the alignment (.bam) files [72]; 3) cluster filtering-we checked for clusters of SNPs (i.e. groups of two or more SNPs occurring in close proximity and on the same branch of the $\mathrm{Y}$ phylogeny) and decided whether to maintain or discard them from the analyses (Additional file 3: Supplementary Text).

\section{Tree reconstruction and validation}

The maximum parsimony phylogenetic tree was reconstructed using the MEGA software [74]. Because we did not assign univocally to $\mathrm{A} 00$ or $\mathrm{A} 0-\mathrm{T}$ the mutational events on branch 1 , the tree root was positioned by default to the midpoint (Additional file 3: Supplementary Text). We identified 25 recurring mutations, 11 triallelic variants and two variant positions whose direction cannot be assigned on the basis of the phylogeny (Additional file 1: Tables S2 and S8 and Additional file 3: Supplementary Text). All these positions were accurately checked in the alignment files. The presence in our list of already identified variants in published papers $[35,48,50-53,57]$ and in the ISOGG dataset [75] made it possible for us to check the efficiency of all the steps from the SNP calling to the tree reconstruction. Our data successfully passed all these control levels.

\section{Mutation rate, dating and star-like index}

The estimate of the mutation rate was obtained using the BEAST software [76]. The input file (nexus format) was loaded onto the BEAUTY suite and we assigned to the four ancient samples the calibrated radiocarbon dates, expressed in years before present (BP): 1) Loschbour [46], 8055 years BP; 2) Kotias [49], 9712 years BP; 3) Bichon [49], 13,665 years BP; 4) Ust'-Ishim [47], 44,890 years BP. We used a GTR nucleotide substitution model under a strict clock or a lognormal relaxed clock and an expansion growth model for the population size, using parameters set as in Trombetta et al. [52]. The output was checked with the Tree Annotator and Tracer platforms. The mutation rate for the $\sim 3.3 \mathrm{Mb}$ analysed here was $0.735 \pm 0.03 \times 10^{-9} /$ site/year, corresponding to about one new mutational event every 408 years.

We applied different methods to estimate the age of the nodes of the tree on the basis of the available information for each node. The nodes of the tree obtained from the NGS data have been dated using both the method implemented by BEAST (with the parameters described above under a strict clock) and the Rho statistics, since we knew the precise number of SNPs downstream of each node. The Rho statistic, its associated standard deviation and the corresponding values expressed in years have been calculated using the Network software [77] (Table 1).

Since we lacked complete information regarding the number of SNPs downstream of the nodes identified from the genotyping, it was not possible to use the Rho statistic to date the new internal nodes. In these cases, we applied two different methods, using the genotyping information of the SNPs on the split branches or extrapolating it from the 1000 Genomes Project [51] Y sequences (Additional file 1: Table S9 and Additional file 3: Supplementary Text).

We used the Rho statistic and its standard deviation to calculate the star-like index of the tree nodes, according to the formula $\rho /\left(n \times S^{2}\right)$, where $\rho$ is the Rho value for the considered node, SD is the Rho standard deviation 
and $n$ is the number of tips downstream of the node $[78,79]$. The star-like index can take values between $1 /$ $n$ and 1 , where 1 corresponds to a perfect star-like topology, characterised by sister lineages splitting from the same node. Usually, values $\geq 0.5$ are considered high star-like indexes [80].

\section{Population analysis}

We selected a total of 142 informative polymorphisms to be genotyped in the whole set of 6065 men from the 128 populations of our lab collection (Fig. 4; Additional file 1: Table S5). The 142 SNPs (including 21 known variants which did not fall within our NGS target region) were chosen on the basis of their phylogenetic position and ethno-geographic distribution, also considering other datasets $[35,48,50-53,57]$ and in the ISOGG [75] (Additional file 1: Table S4). The chosen SNPs have been analysed by PCR and Sanger sequencing or RFLP. Moreover, we extracted the frequency distribution of the selected variants from the NGS data of one Sardinian population [53] and 16 populations from phase 3 of the 1000 Genomes Project [51] (Fig. 4; Additional file 1: Table S5).

\section{Frequency maps}

Frequency maps were drawn on a grid with 100 rows $x$ 78 columns using the Kriging method implemented by the Surfer 6.0 software (Golden Software, Inc., Golden, CO, USA). We used the frequency data of all the African and western Eurasian populations (Fig. 4).

\section{Additional files}

Additional file 1: Table S1. List of samples analysed by NGS. Table S2. List of variant positions in the whole set of $150 \mathrm{Y}$ chromosomes. Table S3. Time estimates (kya) for the nodes of Fig. 2a, obtained with BEAST assuming both a strict and a relaxed clock. Table S4. List of SNPS used for the molecular dissection and population analysis of the four trans-Saharan clades. Table S5. Relative frequencies (percentage) of the A3-M13, E-M2, E-M78 and R-V88 sub-haplogroups in the 145 populations analyzed. Table S6. Twenty-two blocks of the X-degenerate portion of the MSY targeted for the NGS. Table S7. List of the unique fragments of the capture probe set covering the 22 selected MSY regions. Table S8. Description of the two unassigned variant positions. Table S9. Branch assignment of the SNPs that have been extracted from the literature. (XLSX $1131 \mathrm{~kb}$ )

Additional file 2: Figure S1. Eulero-Venn diagram representing the proportion of shared variants between the present study and four recently published papers. Figure S2. Comparison between Rho and BEAST dating methods. Figure S3. A3-M13 phylogeny and distribution. Figure S4. E-M2 phylogeny and distribution. Figure S5. E-M78 phylogeny and distribution. Figure S6. R-V88 phylogeny and distribution. (PDF $472 \mathrm{~kb}$ )

Additional file 3: Supplementary Text. (DOCX $73 \mathrm{~kb}$ )

\section{Abbreviations}

BP: Before present; kya: Thousand years ago; Mb: Megabase; MSY: Malespecific portion of the human Y chromosome; NGS: Next generation sequencing; RFLP: Restriction fragment length polymorphism; SNP: Single nucleotide polymorphism; VCF: Variant call format; WGA: Whole genome amplification

\section{Acknowledgments}

The authors are grateful to all the donors for providing DNA samples and to the people that contributed to the sample collection. In particular, they thank Farha El Chennawi, Anne Cambon-Thomsen, M.S. Issad, Abdellatif Baali, Mohammed Cherkaoui, Mohammed Melhaoui and Eliane Beraud Colomb for their help in the collection of the Moroccan, Algerian and Egyptian Berbers samples; and the National Laboratory for the Genetics of Israeli Populations.

\section{Funding}

This work was supported by the Italian Ministry of Education, University and Research (grants PRIN-MIUR 2012JA4BTY_004 to FC and 2012JA4BTY_003 to AN) and by Sapienza University of Rome (grant numbers C26A153PCN and RM116154C9BE2C3F). ED was supported by a postdoctoral scholarship from the Instituto Pasteur-Fondazione Cenci Bolognetti. The sampling of the Berbers was made within the framework of the Inserm "Réseau Nord/ Sud" No. 490NS1 (Mozabite Berbers), "The Origin of Man, Language and Languages", EUROCORES Programme and benefited from funding by the Région Midi-Pyrénées (Toulouse, France), the CNRS, and the E.C. Sixth Framework Programme under Contract ERASCT-2003-980409.

\section{Availability of data and materials}

The alignment files (.bam) of the targeted sequences of the $104 \mathrm{Y}$ chromosomes analysed here are available through the European Nucleotide Archive (ENA, https://www.ebi.ac.uk/ena) under the study accession number PRJEB24071 (sample accession numbers from ERS2065703 to ERS2065806) [72]. The final set of bases used for the SNP calling are included in this published article (and its supplementary information file; Additional file 1: Table S7). Variant positions analysed during the current study are available in the dbSNP repository (https://www.ncbi.nlm.nih.gov/projects/SNP/) under accession numbers ss2137541472 and from ss3029944616 to ss3029952147 (handle, HUMGEN, ID Y_DEEPSEQ_2017) and are included in this published article (Additional file 1: Table S2).

\section{Authors' contributions}

FC and BT: design and supervision of the project. MB, AF, GDV, MS and DS: experimental analysis. ED and BT: sample selection and bioinformatics analysis. RR, GR, GMP, EW, AC, PA, JMD, PM and AN: sampling and DNA provision. FC, BT and ED: population analysis, statistical analysis and data interpretation. AN: comments on the project and statistical support. FC and ED: manuscript preparation. All authors: approval of the final version of the manuscript.

\section{Ethics approval and consent to participate}

The study was approved by the "Policlinico Umberto I, Sapienza Università di Roma" ethical committee (reference numbers 496/13 and 1016/10), who considered the list of collaborators, anonymity of samples and the compliance with consent regulations. We obtained an appropriate informed consent for DNA samples analysed in this study and all the procedures were in accordance with the Helsinki Declaration.

\section{Competing interests}

The authors declare that they have no competing interests.

\section{Publisher's Note}

Springer Nature remains neutral with regard to jurisdictional claims in published maps and institutional affiliations.

\section{Author details}

'Dipartimento di Biologia e Biotecnologie "C. Darwin", Sapienza Università di Roma, Rome, Italy. ${ }^{2}$ Istituto Pasteur-Fondazione Cenci Bolognetti, Sapienza Università di Roma, Rome, Italy. ${ }^{3}$ Dipartimento di Biologia, Università di Roma "Tor Vergata", Rome, Italy. ${ }^{4}$ Dipartimento di Sanità Pubblica e Malattie Infettive, Sapienza Università di Roma, Rome, Italy. ${ }^{5}$ Botswana-University of Pennsylvania Partnership, Gaborone, Botswana. ${ }^{6}$ Perelman School of Medicine, University of Pennsylvania, Philadelphia, PA, USA. The Swedish Museum of Natural History, Stockholm, Sweden. ${ }^{8}$ Dipartimento di Biologia Ambientale, Sapienza Università di Roma, Rome, Italy. ${ }^{9}$ Istituto Italiano di Antropologia, Rome, Italy. ${ }^{10}$ Centre National de la Recherche Scientifique (CNRS), Université Toulouse-3-Paul-Sabatier, Toulouse, France. ${ }^{11}$ Department of Animal Biology-Anthropology, Biodiversity Research Institute, University of Barcelona, Barcelona, Spain. ${ }^{12}$ Istituto di Biologia e Patologia Molecolari, CNR, Rome, Italy. 


\section{Received: 20 October 2017 Accepted: 19 January 2018}

\section{Published online: 12 February 2018}

\section{References}

1. Brooks N. Cultural responses to aridity in the Middle Holocene and increased social complexity. Quat Int. 2006;151:29-49.

2. Drake NA, Blench RM, Armitage SJ, Bristow CS, White KH. Ancient watercourses and biogeography of the Sahara explain the peopling of the desert. Proc Natl Acad Sci U S A. 2011;108:458-62.

3. Larrasoaña JC, Roberts AP, Rohling EJ. Dynamics of green Sahara periods and their role in hominin evolution. PLoS One. 2013;8:e76514.

4. Scerri EML, Drake NA, Jennings R, Groucutt HS. Earliest evidence for the structure of Homo sapiens populations in Africa. Quat Sci Rev Elsevier BV. 2014;101:207-16.

5. Hublin J-J, Ben-Ncer A, Bailey SE, Freidline SE, Neubauer S, Skinner MM, et al. New fossils from Jebel Irhoud, Morocco and the pan-African origin of Homo sapiens. Nature. 2017:546:289-92.

6. Tierney JE, DeMenocal PB. Abrupt shifts in Horn of Africa hydroclimate since the last glacial maximum. Science. 2013;342:843-6.

7. Sereno PC, Garcea EAA, Jousse H, Stojanowski CM, Saliège J-F, Maga A, et al. Lakeside cemeteries in the Sahara: 5000 years of holocene population and environmental change. PLoS One. 2008;3:e2995.

8. Arredi B, Poloni ES, Paracchini S, Zerjal T, Fathallah DM, Makrelouf M, et al. A predominantly Neolithic origin for Y-chromosomal DNA variation in North Africa. Am J Hum Genet. 2004;75:338-45.

9. Semino O, Magri C, Benuzzi G, Lin AA, Al-Zahery N, Battaglia V, et al. Origin, diffusion, and differentiation of $Y$-chromosome haplogroups $E$ and J: inferences on the neolithization of Europe and later migratory events in the Mediterranean sarea. Am J Hum Genet. 2004;74:1023-34.

10. Chiaroni J, Underhill PA, Cavalli-Sforza LLY. chromosome diversity, human expansion, drift, and cultural evolution. Proc Natl Acad Sci U S A. 2009;106: 20174-9.

11. Beleza S, Gusmão L, Amorim A, Carracedo A, Salas A. The genetic legacy of western Bantu migrations. Hum Genet. 2005;117:366-75.

12. Wood ET, Stover DA, Ehret C, Destro-Bisol G, Spedini G, McLeod H, et al. Contrasting patterns of $Y$ chromosome and mtDNA variation in Africa: evidence for sex-biased demographic processes. Eur J Hum Genet. 2005;13: 867-76.

13. Berniell-Lee G, Calafell F, Bosch E, Heyer E, Sica L, Mouguiama-Daouda P, et al. Genetic and demographic implications of the Bantu expansion: insights from human paternal lineages. Mol Biol Evol. 2009:26:1581-9.

14. Gomes V, Sánchez-Diz P, Amorim A, Carracedo Á, Gusmão L. Digging deeper into East African human Y chromosome lineages. Hum Genet. 2010; 127:603-13.

15. de Filippo C, Barbieri C, Whitten M, Mpoloka SW, Gunnarsdottir ED, Bostoen $\mathrm{K}$, et al. Y-chromosomal variation in Sub-Saharan Africa: insights into the history of Niger-Congo groups. Mol Biol Evol. 2011;28:1255-69.

16. Montano V, Ferri G, Marcari V, Batini C, Anyaele O, Destro-Bisol G, et al. The Bantu expansion revisited: a new analysis of $Y$ chromosome variation in Central Western Africa. Mol Ecol. 2011;20:2693-708.

17. Ansari Pour N, Plaster CA, Bradman N. Evidence from Y-chromosome analysis for a late exclusively eastern expansion of the Bantu-speaking people. Eur J Hum Genet. 2013;21:423-9.

18. Batini C, Ferri G, Destro-Bisol G, Brisighelli F, Luiselli D, Sanchez-Diz P, et al. Signatures of the preagricultural peopling processes in Sub-Saharan Africa as revealed by the phylogeography of early $Y$ chromosome lineages. Mol Biol Evol. 2011;28:2603-13.

19. Scozzari R, Massaia A, Trombetta B, Bellusci G, Myres NM, Novelletto A, et al. An unbiased resource of novel SNP markers provides a new chronology for the human $Y$ chromosome and reveals a deep phylogenetic structure in Africa. Genome Res. Cold Spring Harbor Laboratory Press. 2014;24:535-44.

20. Barbieri C, Hübner A, Macholdt E, Ni S, Lippold S, Schröder R, et al. Refining the $Y$ chromosome phylogeny with southern African sequences. Hum. Genet. Springer. Berlin Heidelberg. 2016;135:541-53.

21. Hassan HY, Underhill PA, Cavalli-Sforza LL, Ibrahim ME. Y- chromosome variation among sudanese: restricted gene flow, concordance with language, geography, and history. Am J Phys Anthropol. 2008;137:316-23.

22. Cruciani F, Santolamazza P, Shen P, Macaulay V, Moral P, Olckers A, et al. A back migration from Asia to Sub-Saharan Africa is supported by highresolution analysis of human Y-chromosome haplotypes. Am J Hum Genet. 2002;70:1197-214.
23. Luis JR, Rowold DJ, Regueiro M, Caeiro B, Cinnioglu C, Roseman C, et al. The Levant versus the Horn of Africa: evidence for bidirectional corridors of human migrations. Am J Hum Genet. 2004;74:532-44.

24. Underhill PA, Shen P, Lin AA, Jin L, Passarino G, Yang WH, et al. Y chromosome sequence variation and the history of human populations. Nat Genet. 2000;26:358-61.

25. Semino O. The genetic legacy of Paleolithic Homo sapiens sapiens in extant Europeans: a Y chromosome perspective. Science. 2000;290:1155-9.

26. Nebel A, Filon D, Brinkmann B, Majumder PP, Faerman M, Oppenheim A. The Y chromosome pool of Jews as part of the genetic landscape of the Middle East. Am J Hum Genet. 2001;69:1095-112.

27. Cinnioglu C, King R, Kivisild T, Kalfoglu E, Atasoy S, Cavalleri GL, et al. Excavating Y-chromosome haplotype strata in Anatolia. Hum Genet. 2004; 114:127-48

28. Shen P, Lavi T, Kivisild T, Chou V, Sengun D, Gefel D, et al. Reconstruction of patrilineages and matrilineages of Samaritans and other Israeli populations from Y-Chromosome and mitochondrial DNA sequence Variation. Hum Mutat. 2004;24:248-60

29. Flores C, Maca-Meyer N, Larruga JM, Cabrera VM, Karadsheh N, Gonzalez AM. Isolates in a corridor of migrations: a high-resolution analysis of $Y$ chromosome variation in Jordan. J Hum Genet. 2005;50:435-41.

30. Francalacci P, Morelli L, Angius A, Berutti R, Reinier F, Atzeni R, et al. LowPass DNA Sequencing of 1200 Sardinians reconstructs European $Y$ chromosome phylogeny. Science. 2013;341:565-9.

31. Robino C, Crobu F, Di Gaetano C, Bekada A, Benhamamouch S, Cerutti N, et al. Analysis of Y-chromosomal SNP haplogroups and STR haplotypes in an Algerian population sample. Int J Leg Med. 2008;122:251-5.

32. Fadhlaoui-Zid K, Haber M, Martínez-Cruz B, Zalloua P, Benammar Elgaaied A, Comas D. Genome-wide and paternal diversity reveal a recent origin of human populations in North Africa. PLoS One. 2013;8:e80293.

33. Cruciani F, La Fratta R, Santolamazza P, Sellitto D, Pascone R, Moral P, et al. Phylogeographic analysis of haplogroup E3b (E-M215) Y chromosomes reveals multiple migratory events within and out of Africa. Am J Hum Genet. 2004;74:1014-22

34. Cruciani F, La Fratta R, Trombetta B, Santolamazza P, Sellitto D, Colomb EB, et al. Tracing past human male movements in Northern/Eastern Africa and Western Eurasia: new clues from Y-Chromosomal haplogroups E-M78 and JM12. Mol. Biol. Evol. 2007:24:1300-11.

35. Trombetta B, D'Atanasio E, Massaia A, Ippoliti M, Coppa A, Candilio F, et al. Phylogeographic refinement and large scale genotyping of human $Y$ chromosome haplogroup E provide new insights into the dispersal of early pastoralists in the African continent. Genome Biol Evol. 2015;7:1940-50.

36. lacovacci G, D'Atanasio E, Marini O, Coppa A, Sellitto D, Trombetta B, et al. Forensic data and microvariant sequence characterization of 27 Y-STR loci analyzed in four Eastern African countries. Forensic Sci Int Genet. 2017;27: 123-31. http://linkinghub.elsevier.com/retrieve/pii/S1872497316302484

37. Cruciani F, Trombetta B, Sellitto D, Massaia A, Destro-Bisol G, Watson E, et al. Human Y chromosome haplogroup R-V88: a paternal genetic record of early mid Holocene trans-Saharan connections and the spread of Chadic languages. Eur J Hum Genet. 2010;18:800-7.

38. Zalloua PA, Xue Y, Khalife J, Makhoul N, Debiane L, Platt DE, et al. YChromosomal diversity in Lebanon is structured by recent historical events. Am J Hum Genet. 2008;82:873-82.

39. Morelli L, Contu D, Santoni F, Whalen MB, Francalacci P, Cucca F. A Comparison of $Y$-chromosome variation in Sardinia and Anatolia is more consistent with cultural rather than demic diffusion of agriculture. PLoS One. 2010;5:e10419.

40. González M, Gomes W, López-Parra AM, Amorim AA, Carracedo Á, SánchezDiz $P$, et al. The genetic landscape of Equatorial Guinea and the origin and migration routes of the $Y$ chromosome haplogroup R-V88. Eur J Hum Genet. 2013;21:324-31.

41. Busby GB, Band G, Le QS, Jallow M, Bougama E, Mangano VD, et al. Admixture into and within sub-Saharan Africa. Elife. 2016;5:e15266.

42. Henn BM, Botigué LR, Gravel S, Wang W, Brisbin A, Byrnes JK, et al. Genomic ancestry of North Africans supports back-to-Africa migrations. PLoS Genet. 2012:8:e1002397.

43. Pagani L, Schiffels S, Gurdasani D, Danecek P, Scally A, Chen Y, et al. Tracing the route of modern humans out of Africa by using 225 human genome sequences from Ethiopians and Egyptians. Am J Hum Genet. 2015;96:986-91.

44. Schuenemann VJ, Peltzer A, Welte B, van Pelt WP, Molak M, Wang C-C, et al. Ancient Egyptian mummy genomes suggest an increase of Sub-Saharan African ancestry in post-Roman periods. Nat Commun. 2017;8:15694. 
45. Drmanac R, Sparks A, Callow M. Human genome sequencing using unchained base reads on self-assembling DNA nanoarrays. Science. 2010; 327:78-81

46. Lazaridis I, Patterson N, Mittnik A, Renaud G, Mallick S, Kirsanow K, et al. Ancient human genomes suggest three ancestral populations for presentday Europeans. Nature. 2014;513:409-13.

47. Fu Q, Li H, Moorjani P, Jay F, Slepchenko SM, Bondarev AA, et al. Genome sequence of a 45,000-year-old modern human from western Siberia. Nature. 2014;514:445-9.

48. Karmin M, Saag L, Vicente M, Sayres MAW, Järve M, Talas UG, et al. A recent bottleneck of $Y$ chromosome diversity coincides with a global change in culture. Genome Res. 2015;25:459-66.

49. Jones ER, Gonzalez-Fortes G, Connell S, Siska V, Eriksson A, Martiniano R, et al. Upper Palaeolithic genomes reveal deep roots of modern Eurasians. Nat Commun. 2015:6:8912.

50. Hallast $P$, Batini C, Zadik D, Maisano Delser P, Wetton JH, Arroyo-Pardo E, et al. The Y-chromosome tree bursts into leaf: 13,000 high-confidence SNPs covering the majority of known clades. Mol Biol Evol. 2015;32:661-73.

51. Poznik GD, Xue Y, Mendez FL, Willems TF, Massaia A, Wilson Sayres MA, et al. Punctuated bursts in human male demography inferred from 1,244 worldwide Y-chromosome sequences. Nat Genet. 2016;48:593-9.

52. Trombetta B, D'Atanasio E, Massaia A, Myres NM, Scozzari R, Cruciani F, et al Regional differences in the accumulation of SNPs on the male-specific portion of the human $Y$ chromosome replicate autosomal patterns: implications for genetic dating. PLoS One. 2015;10:e0134646.

53. Francalacci $P$, Sanna D, Useli A, Berutti R, Barbato M, Whalen MB, et al. Detection of phylogenetically informative polymorphisms in the entire euchromatic portion of human Y chromosome from a Sardinian sample. BMC Res. 2015;8:174

54. Wright J. The trans-Saharan slave trade. London and New York: Routledge: 2007.

55. Tishkoff SA, Reed FA, Friedlaender FR, Ehret C, Ranciaro A, Froment A, et al, The genetic structure and history of Africans and African Americans. Science. 2009;324:1035-44.

56. Haber M, Mezzavilla M, Bergström A, Prado-Martinez J, Hallast P, Saif-Ali R, et al. Chad genetic diversity reveals an African history marked by multiple Holocene Eurasian migrations. Am J Hum Genet. 2016;99:1316-24.

57. Batini C, Hallast P, Zadik D, Delser PM, Benazzo A, Ghirotto S, et al. Large-scale recent expansion of European patrilineages shown by population resequencing. Nat Commun. 2015;6:7152

58. Patin E, Lopez M, Grollemund R, Verdu P, Harmant C, Quach H, et al. Dispersals and genetic adaptation of Bantu-speaking populations in Africa and North America. Science. 2017;356:543-6.

59. Hellenthal G, Busby GBJ, Band G, Wilson JF, Capelli C, Falush D, et al. A genetic atlas of human admixture history. Science. 2014;343:747-51.

60. Arauna LR, Mendoza-Revilla J, Mas-Sandoval A, Izaabel H, Bekada A, Benhamamouch $S$, et al. Recent historical migrations have shaped the gene pool of Arabs and Berbers in North Africa. Mol Biol Evol. 2017;34:318-29.

61. Richards M, Rengo C, Cruciani F, Gratrix F, Wilson JF, Scozzari R, et al. Extensive female-mediated gene flow from sub-Saharan Africa into near eastern Arab populations. Am J Hum Genet. 2003;72:1058-64.

62. Manning K, Timpson A. The demographic response to Holocene climate change in the Sahara. Quat Sci Rev. 2014;101:28-35.

63. Kuper R, Kröpelin S. Climate-controlled Holocene occupation in the Sahara: motor of Africa's evolution. Science. 2006;313:803-7.

64. deMenocal P, Ortiz J, Guilderson T, Adkins J, Sarnthein M, Baker L, et al. Abrupt onset and termination of the African Humid Period: rapid climate responses to gradual insolation forcing. Quat Sci Rev. 2000;19:347-61.

65. Trombetta B, Cruciani F, Sellitto D, New SRA. topology of the human Y chromosome haplogroup E1b1 (E-P2) revealed through the use of newly characterized binary polymorphisms. PLoS One. 2011;6:e16073.

66. Skaletsky H, Kuroda-Kawaguchi T, Minx PJ, Cordum HS, Hillier L, Brown LG, et al. The male-specific region of the human $Y$ chromosome is a mosaic of discrete sequence classes. Nature. 2003:423:825-37.

67. Bailey JA, Yavor AM, Massa HF, Trask BJ, Eichler EE. Segmental duplications: organization and impact within the current human genome project assembly. Genome Res. 2001;11:1005-17.

68. Bailey JA. Recent segmental duplications in the human genome. Science. 2002;297:1003-7

69. Jurka J. Repbase Update: a database and an electronic journal of repetitive elements. Trends Genet. 2000;16:418-20.
70. Li H, Durbin R. Fast and accurate short read alignment with Burrows-Wheeler transform. Bioinformatics. 2009:25:1754-60.

71. Li H, Handsaker B, Wysoker A, Fennell T, Ruan J, Homer N, et al. The Sequence Alignment/Map format and SAMtools. Bioinformatics. 2009:25:2078-9.

72. D'Atanasio E, Trombetta B, Bonito M, Finocchio A, Di Vito G, Seghizzi M, et al. The peopling of the last Green Sahara revealed by high-coverage resequencing of trans-Saharan patrilineages. European Nucleotide Archive. http://www.ebi.ac.uk/ena/data/view/PRJEB24071

73. Li H. A statistical framework for SNP calling, mutation discovery, association mapping and population genetical parameter estimation from sequencing data. Bioinformatics. 2011;27:2987-93.

74. Tamura K, Stecher G, Peterson D, Filipski A, Kumar S. MEGA6: Molecular Evolutionary Genetics Analysis Version 6.0. Mol Biol Evol. 2013;30:2725-9.

75. International Society of Genetic Genealogy. Y-DNA Haplogroup Tree, version 10.59. 2017. http://www.isogg.org/tree/. Accessed 2015 Oct 27.

76. Drummond AJ, Rambaut A. BEAST: Bayesian evolutionary analysis by sampling trees. BMC Evol Biol. 2007;7:214

77. Bandelt HJ, Forster P, Rohl A. Median-joining networks for inferring intraspecific phylogenies. Mol Biol Evol. 1999;16:37-48.

78. Torroni A, Bandelt H-J, D'Urbano L, Lahermo P, Moral P, Sellitto D, et al. $m t D N A$ analysis reveals a major late Paleolithic population expansion from Southwestern to Northeastern Europe. Am J Hum Genet. 1998:62:1137-52.

79. Saillard J, Forster P, Lynnerup N, Bandelt H-J, mtDNA NS. variation among Greenland Eskimos: The edge of the Beringian expansion. Am J Hum Genet 2000;67:718-26

80. Achilli A, Perego UA, Bravi CM, Coble MD, Kong QP, Woodward SR, et al. The Phylogeny of the Four Pan- American MtDNA Haplogroups: Implications for Evolutionary and Disease Studies. PLoS One. 2008:3:e1764

\section{Submit your next manuscript to BioMed Central and we will help you at every step:}

- We accept pre-submission inquiries

- Our selector tool helps you to find the most relevant journal

- We provide round the clock customer support

- Convenient online submission

- Thorough peer review

- Inclusion in PubMed and all major indexing services

- Maximum visibility for your research

Submit your manuscript at www.biomedcentral.com/submit
) Biomed Central 